\title{
What factors are associated with premature death among professional baseball players in Japan?
}

\author{
Hideyuki Kanda ${ }^{1,2^{*}}$, Satoshi Tsuboi ${ }^{2,3}$, Masayoshi Tsuji ${ }^{2}$, Takeyasu Kakamu ${ }^{2}$, Yayoi Mori ${ }^{2}$ \\ Takehito Hayakawa ${ }^{2}$, Tetsuhito Fukushima ${ }^{2}$ \\ ${ }^{1}$ Department of Epidemiology and Public Health, School of Medicine, Yokohama City University, Yokohama, Japan; \\ *Corresponding Author: hkanda@yokohama-cu.ac.jp \\ ${ }^{2}$ Department of Hygiene and Preventive Medicine, Fukushima Medical University, Fukushima, Japan \\ ${ }^{3}$ Department of Public Health, Jichi Medicine University, Tochigi, Japan
}

Received 15 February 2013; revised 21 March 2013; accepted 6 April 2013

Copyright (c) 2013 Hideyuki Kanda et al. This is an open access article distributed under the Creative Commons Attribution License, which permits unrestricted use, distribution, and reproduction in any medium, provided the original work is properly cited.

\begin{abstract}
The aim of this study is to clarify factors related to premature death among Japanese professional baseball players by a case-control analysis. The subjects are two matching groups of 622 Japan Professional Baseball (JPB) league players, those deceased and those surviving. Cases and controls are matched by birth year. All players debuted on the first string between 1934 and 2003, and are listed in The Official Baseball Encyclopedia of Japan. To compare means and frequencies of characteristics between deceased and surviving groups, t-tests and chi-square tests were used. A logistic regression analysis was assessed contributions of each independent variable on death. Significant differences between deceased and surviving players were observed in this study; deceased players had higher body mass indexes and longer careers. Furthermore, logistic regression analysis confirmed that body mass index and career length were statistically significant determinants of death for baseball players. This is the first report to examine factors of death for professional baseball players except employing data attained from Major League Baseball.
\end{abstract}

Keywords: Factors of Death; Professional Baseball Player; Body Mass Index; Career Length

\section{INTRODUCTION}

For the general population, playing sports presumably contributes to longer life and better health [1-3]. How- ever, for professional athletes, evidence relating longevity to their sporting activity is equivocal [4,5]. Longevity studies among athletes have yielded conflicting results with some previous studies reporting lower than expected mortality [6]; whereas others have not found significant difference [7]. In contrast to studies of whether professional sports affect longevity, there are few studies what factors are associated with premature death among professional athletes [8].

Factors pertaining to the longevity of baseball players remain unconfirmed because we find only one paper written about the longevity among baseball players [8]. Then, the data in this argument derive from players in the American major league baseball (MLB). With the increasing popularity of baseball, professional baseball leagues have now been established all over the world. Outside of the USA, baseball is especially popular in East Asia, in countries such as Japan, South Korea and Taiwan [9]. The Japan Professional Baseball (JPB) League, established in 1936, has over 70 years of history [10]. It also provides an official database from which to examine some of factors associated with premature death because it has a history of detailed statistics. JPB data are the basis for this study of factors related to death among professional baseball players.

In the present study, we have clarified the factors associated with premature death among professional baseball players with JPB data. This study design was a casecontrol study with deceased players as cases and surviving players with matching birth years as controls.

\section{METHODS}

\subsection{Data Source and Categories}

Data for all JPB league players who debuted on the first string between 1934 and 2003 were compiled using 
The Official Baseball Encyclopedia 2004 of Japan [10]. The date of birth, date of death, height, weight, throwing and batting handedness, length of career, player position, and educational background were recorded for each player. Their body mass indexes (BMI) were calculated as weight $(\mathrm{kg})$ divided by the square of height $(\mathrm{m})$. Each player's handedness was divided into three categories (right handed for both throwing and batting, left handed for both throwing and batting, other). Categories under educational background include "graduated" and "dropout". Player positions were separated into four categories (pitcher, catcher, infielder, outfielder). "Position" for each player was defined as the position the player occupied for most of his career. If a baseball player was deceased, longevity was calculated by subtracting the date of birth from the date of death.

\subsection{Participants}

Of the 4238 male players listed on The Official Baseball Encyclopedia as having made their professional debut between 1934 and 2003, 380 were deceased and 3888 were still alive as of March 2004. Of these, 36 deceased players were excluded from the analysis because 25 died during World War II, and sufficient data were lacking on the other 11 people. In addition, a further 39 deceased players were excluded because there were no controls born in the same year. This was especially true for older players. This study was therefore a case-control study with 305 deceased players born between 1906 and 1968 as cases, and 305 surviving players with matching birth years as controls.

\subsection{Statistical Analysis}

To compare means and frequencies of the variables between cases and controls, t-tests were used for continuous variables such as longevity, BMI, age of debut, and length of career, while chi-square tests were used for categorical variables such as handedness, educational background and player position. Multiple logistic regression analysis was used to assess the contribution of each independent variable to death. The Statistical Package for the Social Sciences (SPSS Japan Inc. version 16.0 J, Tokyo, Japan) was used to conduct the analyses. All probability values were two-tailed, and all confidence intervals were estimated at the $95 \%$ level.

\section{RESULTS}

\subsection{Characteristics between Deceased and Surviving JPB Players}

Table 1 shows the characteristics between 305 deceased and 305 surviving JPB players. The overall difference in life expectancy between deceased players and
Table 1. Characteristics between 311 deceased and 311 survivaling Japanese professional baseball players in 2004.

\begin{tabular}{|c|c|c|c|}
\hline \multirow[b]{2}{*}{ Characteristics } & \multicolumn{3}{|c|}{ Comparison of deceased and surviving players } \\
\hline & $\begin{array}{c}\text { Deceased } \\
\text { players } N=311\end{array}$ & $\begin{array}{c}\text { Surviving } \\
\text { players } \mathrm{N}=311\end{array}$ & P-value \\
\hline Birth year (year, \pm SD) & $1927 \pm 11$ & $1927 \pm 11$ & $0.97^{\mathrm{a}}$ \\
\hline 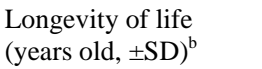 & $61.6 \pm 15.5$ & $77.2 \pm 11.2$ & $<0.01^{\mathrm{a}}$ \\
\hline $\begin{array}{l}\text { Body mass index } \\
\left(\mathrm{kg} / \mathrm{m}^{2}, \pm \mathrm{SD}\right)\end{array}$ & $23.1 \pm 1.8$ & $22.6 \pm 1.6$ & $<0.01^{\mathrm{a}}$ \\
\hline $\begin{array}{l}\text { Frequency of over } \\
\text { BMI } 25 \mathrm{~kg} / \mathrm{m}^{2} \\
\text { (Number, (\%)) }\end{array}$ & $47(15.1 \%)$ & $25(8.0 \%)$ & $<0.01^{\mathrm{c}}$ \\
\hline $\begin{array}{l}\text { Age of debuted } \\
\text { (years old, } \pm \text { SD) }\end{array}$ & $22.0 \pm 4.2$ & $22.0 \pm 3.9$ & $0.94^{\mathrm{a}}$ \\
\hline $\begin{array}{l}\text { Length of career } \\
\text { (years, } \pm \text { SD) }\end{array}$ & $7.7 \pm 4.7$ & $4.9 \pm 4.1$ & $<0.01^{\mathrm{a}}$ \\
\hline \multicolumn{4}{|l|}{$\begin{array}{l}\text { Handedness (Both } \\
\text { throwing and batting } \\
\text { (number, \%)) }\end{array}$} \\
\hline Right hander & 252 (81.0\%) & 257 (82.5\%) & $0.87^{\mathrm{C}}$ \\
\hline Left hander & 49 (15.8\%) & 45 (14.6\%) & \\
\hline Other & $10(3.2 \%)$ & $9(2.9 \%)$ & \\
\hline \multicolumn{4}{|l|}{$\begin{array}{l}\text { Educational } \\
\text { backgrounds }\end{array}$} \\
\hline $\begin{array}{l}\text { (number, \%) } \\
\text { JHS }^{\mathrm{d}} \\
\text { SHS }^{\mathrm{e}} \\
\text { University or College }\end{array}$ & $\begin{array}{l}42(13.5 \%) \\
129(41.5 \%) \\
140(45.0 \%)\end{array}$ & $\begin{array}{c}33(10.6 \%) \\
173(55.6 \%) \\
105(33.8 \%)\end{array}$ & $<0.01^{\mathrm{c}}$ \\
\hline \multicolumn{4}{|l|}{$\begin{array}{l}\text { Player position } \\
\text { (number, \%) }\end{array}$} \\
\hline $\begin{array}{l}\text { Pitcher } \\
\text { Catcher }\end{array}$ & $\begin{array}{c}112(36.0 \%) \\
38(12.2 \%)\end{array}$ & $\begin{array}{l}91 \text { (29.3\%) } \\
40(12.9 \%)\end{array}$ & $0.16^{\mathrm{c}}$ \\
\hline Infielder & 82 (26.4\%) & 105 (33.8\%) & \\
\hline Outfielde & $79(25.4 \%)$ & 75 (24.1\%) & \\
\hline
\end{tabular}

${ }^{\mathrm{a}} \mathrm{P}$-value for Student t-test; ${ }^{\mathrm{b}}$ Deceased players average were shown the age of death on deceased players and surviving players were shown the average age in 31 March, 2004; ${ }^{\mathrm{C}} \mathrm{P}$-value for qui-square test; ${ }^{\mathrm{d} J H S}$ : highest education level achieved is junior high school or less; 'SHS: highest education level achieved entry to senior high school.

controls was 15.6 years (61.4 vs. 77.0 years; $\mathrm{P}<0.01$ ). Deceased players have statistically higher BMI, longer careers, and a higher educational background by t-test or chi-square test. Both mean BMI and prevalence of BMI 25 and over were higher among deceased players than controls (23.1 vs. $22.6 \mathrm{~kg} / \mathrm{m}^{2}, \mathrm{P}<0.01 ; 14.8 \%$ vs. $8.2 \%$, $\mathrm{P}=0.02)$. Then, difference in mean length of career between deceased players and controls was 2.8 years ( 7.7 vs. 4.9 years; $\mathrm{P}<0.01)$. Deceased players had more university or college education and less senior high school education than controls in the educational background (University or College $44.3 \%$ vs. $33.4 \%$, Senior High School $42.0 \%$ vs. $56.1 \%$; $\mathrm{P}<0.01$ )

\subsection{Factors Related to Death among JPB Players}

Table 2 shows the odds ratios and 95\% confidential intervals of each independent factor related to death 
Table 2. Odds ratio and 95\% confidence intervals to death by multiple logistic regression analysis among Japanese professional baseball players.

\begin{tabular}{lcc}
\hline \multirow{1}{*}{ Variables } & \multicolumn{2}{c}{$\begin{array}{c}\text { Odds ratio and 95\% confidence } \\
\text { intervals }\end{array}$} \\
\cline { 2 - 3 } & Odds & $\begin{array}{c}\text { 95\% confidence } \\
\text { intervals }\end{array}$ \\
\hline $\begin{array}{l}\text { Body mass index }\left(\mathrm{kg} / \mathrm{m}^{2}\right) \\
\text { Length of career (year) }\end{array}$ & 1.11 & $1.00-1.23$ \\
$\begin{array}{l}\text { Educational backgrounds } \\
\text { JHS }\end{array}$ & 1.15 & $1.12-1.20$ \\
$\begin{array}{l}\text { SHS } \\
\text { University or College }\end{array}$ & 1.00 & \\
\hline
\end{tabular}

aHS: highest education level achieved is junior high school or less; ${ }^{\mathrm{b}} \mathrm{SHS}$ : highest education level achieved entry to senior high school.

among JPB players using multiple logistic regression analysis. Longer length of career was statistically significant death determinants among professional baseball players (Odds ratio 1.15, 95\% confidence interval 1.10 to 1.20). It was also observed that BMI and educational background did not reach statistical significance using a logistic regression analysis.

\section{DISCUSSION}

The present study suggests a higher BMI and longer career length as factors related to death among JPB players. Although sporting activity is generally expected to contribute to longevity, a long career is one of factors that lead to premature death for this specific group of athletes who assume sports as a professional occupation. This is the first report to examine factors of death for professional baseball players except employing data attained from Major League Baseball.

\subsection{Longer Careers and Premature Death}

Our result, which showed that longer careers are associated with premature death, may depend on the influence of physical and mental conditions among professional baseball players. The JPB player who makes a good grade tends to be employed for a long time. The good batter takes place of a pinch hitter from a start member, and the good pitcher takes place of a closer from a starter. The load of players may act on the death because this difference of background may affect the length of career. Then, professional baseball players play over 130 games during a season that spans over half of a year, and undergo training and pre-season games during the other half of the year. A long career for professional baseball players demands a consistently high level of physical and mental performance in order to renew yearto-year employment contracts. They also may be subjected to high mental and physical stress for prolonged periods, especially during a long career. Maintaining a high ability in both physical and mental health may make increase susceptibility to life-threatening conditions [11, 12]. Our research found that a long career consistently increased the likelihood of premature death even among professional baseball players. They may be difficult to get off from long-term burden with both physical and mental performance not only in his career but also after retirement [13]. For author/s of only one affiliation: To change the default, adjust the template as follows.

\subsection{Higher BMI and Premature Death}

On the other hands, professional baseball players may be more susceptible to diseases which lead to death, if they maintain the dietary habits of active players, such as high calorie diets, after retirement that they decrease their physical activity. A previous study on MLB players also points out that a high BMI is a contributing factor for death among players [8]. Although it achieved borderline significance in statistics when analyzed using logistic regression analysis, our results also suggested that one of the factors of death for professional baseball players may be a higher BMI. The relationship between longevity and BMI, which is one of results led to take high calorie diets, has been researched for the general population. However, it is difficult to understand relationship among professional baseball players due to keeping professional fit. Thus, this relationship between longevity and high BMI among professional baseball players exists in both the US and Japan, suggesting a common death characteristic among professional baseball players. Nutrition, physical exertion, extracurricular risk behavior, etc., may be supposed, but data are insufficient in these areas. A high BMI amongst professional baseball players may mean an increase in muscle as a result of such physical training. A recent study reports that a high demand of physical labor runs a high risk for all-cause mortality [11]. High physical labor may lead to death because to the body is continuously abused to keep up its physical ability. However, the relationship between longevity and BMI was not as strong as our findings with length of career. The full mechanism of the survival disadvantage among professional baseball players is not known.

\subsection{Limitations}

There are some limitations in the present study. First, we could not assess the cause of death or other common risk factors for death, such as smoking and alcohol consumption, because the data used was secondary data from the Official Baseball Encyclopedia. Also we could not assess effects of body composition, such as relative muscle mass, for lack of these details due to the source of data. Second, this was a case-control study, which 
may be intrinsically biased.

\subsection{Conclusion}

In conclusion, we clarified death factors among JPB players as being a longer length of career. Although sporting activity is generally expected to contribute to longevity, a long career is one of factors that lead to premature death for this specific group of athletes who assume sports as a professional occupation. This study suggests that professional baseball players with long careers should be more attentive to personal health issues, especially insomuch as they are role models for young sports enthusiasts.

\section{ACKNOWLEDGEMENTS}

We are grateful to Ms. Ayumi Okuyama, Ms. Satoko Shimizu for assembling, inputting, and management of the data, and to Mr. William McMichael and Dr. Kenneth Nollet for English editing of the manuscript.

\section{REFERENCES}

[1] Saase, J.L., Noteboom, W.M. and Vandenbroucke, J.P. (1990) Longevity of men capable of prolonged vigorous physical exercise: A 32-year follow up of 2259 participants in the Dutch eleven cities ice skating tour. British Medical Journal, 301, 1409-1411. doi:10.1136/bmj.301.6766.1409

[2] Lee, I.M., Hsieh, C.C. and Paffenbarger Jr., R.S. (1995) Exercise intensity and longevity in men. The Harvard Alumni Health Study, JAMA, 274, 1132-1133.

[3] Nocon, M., Hiemann, T., Müller-Riemenschneider, F., Thalau, F., Roll, S. and Willich, S.N. (2008) Association of physical activity with all-cause and cardiovascular mortality: A systematic review and meta-analysis. European Journal of Cardiovascular Preventive Rehabilitation, 15, 239-246. doi:10.1097/HJR.0b013e3282f55e09
[4] Sarna, S., Sahi, T., Koskenvuo, M. and Kaprio, J. (1993) Increased life expectancy of world class male athletes. Medicine and Science in Sports Exercise, 25, 237-244. doi:10.1249/00005768-199302000-00013

[5] Sarna, S., Kaprio, J., Kujala, U.M. and Koskenvuo, M. (1997) Health status of former elite athletes. The Finnish Experience Aging, 9, 35-41.

[6] Schnohr, P. (1971) Longevity and causes of death in male athletic champions. Lancet, 2, 1364-1365. doi:10.1016/S0140-6736(71)92377-4

[7] Waterbor, J., Cole, P., Delzeli, E. and Andjelkovitz, D. (1988) The mortality experience of major league baseball players. New England Journal of Medicine, 318, 12781280. doi:10.1056/NEJM198805123181917

[8] Abel, E.L. and Kruger, M.L. (2005) The longevity of Baseball Hall of Famers compared to other players. Death Studies, 29, 959-963. doi:10.1080/07481180500299493

[9] Bjarkman, P.C. (2005) Diamonds around the globe: The encyclopedia of international baseball. Greenwood Press, Westport.

[10] Nippon Professional Baseball (2004) The Official Baseball Encyclopedia. 4th Edition, Baseball Magazine Sha Co., Ltd, Tokyo.

[11] Eve, B., Wild, P., Massin, N., Meyer, J.P., Sierra, C.O., Fontana, J.-M., Benamghar, L., Mur, J.-M., Ravaud, J.-F., Guillemin, F. and Chau, N. (2008) Association of physical job demands, smoking and alcohol abuse with subsequent premature mortality: A 9-year follow-up population-based study. Journal of Occupational Health, 50, 31-40. doi:10.1539/joh.50.31

[12] Tanno, K., Sakata, K. and Japan Collaborative Cohort Study for Evaluation of Cancer (2007) Psychological factors and mortality in the Japan Collaborative Cohort Study for Evaluation of Cancer (JACC). Asian Pacific Journal of Cancer Prevention, 8, 113-122.

[13] Mare, R.D. (1990) Socioeconomic careers and differential mortality among older men in the United States. In: Vallin, J., D’Souza, S. and Palloni, A., Eds., Measurement and Analysis of Mortality: New Approaches, Clarendon Press, Oxford, 362-387. 